\title{
Elevated mammaglobin ( $h$-MAM) expression in breast cancer is associated with clinical and biological features defining a less aggressive tumour phenotype
}

\author{
MJ Núñez-Villar¹, F Martínez-Arribas ${ }^{1}$, M Pollán ${ }^{2}$, AR Lucas ${ }^{1}$, J Sánchez ${ }^{1,3}$, A Tejerina ${ }^{1}$ \\ and J Schneider ${ }^{1,4}$ \\ ${ }^{1}$ Fundación Tejerina-Centro de Patología de la Mama, Madrid, Spain \\ ${ }^{2}$ Centro Nacional de Epidemiología, Departamento de Epidemiología del Cáncer, Madrid, Spain \\ 3Universidad de Alcalá, Facultad de Medicina, Madrid, Spain \\ ${ }^{4}$ Universidad Rey Juan Carlos, Facultad de Ciencias de la Salud, Madrid, Spain \\ Corresponding author: J Schneider (e-mail: schneider@teleline.es))
}

Received: 26 Aug 2002 Revisions requested: 21 Oct 2002 Revisions received: 16 Dec 2002 Accepted: 12 Feb 2003 Published: 6 Mar 2003

Breast Cancer Res 2003, 5:R65-R70 (DOI 10.1186/bcr587)

(c) 2003 Núñez-Villar et al., licensee BioMed Central Ltd (Print ISSN 1465-5411; Online ISSN 1465-542X). This is an Open Access article: verbatim copying and redistribution of this article are permitted in all media for any purpose, provided this notice is preserved along with the article's original URL.

\begin{abstract}
Background: Mammaglobin ( $h-M A M)$ is expressed mainly by breast epithelial cells, and this feature has been used to detect circulating breast cancer cells and occult metastases in sentinel axillary lymph nodes of breast cancer patients. However, the biological role of mammaglobin is completely unknown.

Methods: We studied 128 fresh-frozen breast cancer specimens by means of reverse transcriptase-polymerase chain reaction and quantified their $h-M A M$ mRNA expression. This was then correlated with histological and nuclear grade, oestrogen and progesterone receptor expression, c-erb-B2 and mutant p53 expression, as well as with cellular proliferation measured by means of the Ki67 labelling index, DNA ploidy and S-phase, and finally with the presence or not of invaded axillary nodes in the mastectomy specimen.
\end{abstract}

\begin{abstract}
Results: In the univariate analysis, high $h-M A M$ expression (above the median for the whole group) correlated significantly $(P<0.05)$ with oestrogen and progesterone receptor expression, diploid DNA content, low Ki67 labelling index, low nuclear grade and almost significantly $(P=0.058)$ with the absence of axillary nodal invasion in the mastectomy specimen. In a final, multivariate model, only progesterone receptor expression, diploid DNA content and absence of nodal invasion were found to be independently associated with high $h-M A M$ expression.
\end{abstract}

Conclusion: All of the features associated with mammaglobin expression reflect, without exception, a less aggressive tumour phenotype. Further studies are needed to clarify whether this is attributable to $h-M A M$ expression itself, or to another mechanism of which mammaglobin expression forms part.

Keywords: breast, cancer, mammaglobin, reverse transcriptase polymerase chain reaction

\section{Introduction}

The human mammaglobin ( $h-M A M)$ gene was recently cloned by Watson and colleagues [1]. It maps to chromosome 11q12-13, and the amino acid sequence it encodes is similar to that of epithelial secretory proteins belonging to the uteroglobin family, all of which are encoded by genes clustered on the same chromosomal region [2]. Mammaglobin expression has been observed in breast epithelial cells, but not in myoepithelial or stromal breast cells [3]. Zach and colleagues [4] were not able to detect mammaglobin expression by means of reverse transcriptase-polymerase chain reaction (RT-PCR) in the human uterus, ovary or leukocytes [4]. However, Grünewald and colleagues [5], using the same technique, have shown mammaglobin to be expressed in normal and malignant tissues from the ovary, uterus and cervix, as well as in both prostatic hyperplasia and cancer. In a previous paper, the same authors had used mammaglobin experimentally to 
detect circulating breast cancer cells, showing by means of RT-PCR a sensitivity threshold of one tumour cell per million mononuclear blood cells [6]. Mammaglobin has also been used for detecting occult metastases in sentinel axillary lymph nodes of breast cancer patients by means of RT-PCR [7].

However, the biological role of mammaglobin in breast tissue, and by extension in breast cancer, is completely unknown. The biologically active form seems to be a complex formed between mammaglobin and another member of the family, BU101, also known as lipophilin B [8], so its mechanism of action might form part of a more complicated chain involving several elements.

In the present study we have quantified the expression of mammaglobin in a series of human breast carcinomas, and have correlated this expression with all available clini$\mathrm{cal}$ and molecular parameters, with the intent of clarifying its biological role in breast cancer.

\section{Materials and methods}

The tumours were obtained from patients operated on for breast cancer at Fundación Tejerina, Madrid, Spain, after having obtained written informed consent for doing so before surgery. The tumour fraction was identified at the time of intraoperative biopsy (which was performed in all patients), to exclude, to any possible extent, contamination from normal breast tissue. The specimens were either immediately snap-frozen in liquid $\mathrm{N}_{2}$, or immersed in RNAlater ${ }^{\mathrm{TM}}$ (Ambion Inc, Austin, Texas, USA) and frozen at $-80^{\circ} \mathrm{C}$ over the next 24 hours.

In all, 128 tumour specimens were studied, of which 104 were infiltrating ductal carcinomas (IDC), 20 were lobular infiltrating carcinomas (LIC) and 4 were tubular carcinomas. These fresh tumour specimens were used for the extraction of RNA and RT-PCR and also for flow cytometry. The immunohistochemical procedures described below, in their turn, were performed on slides from routinely processed paraffin blocks used for conventional pathological examination.

Of the 128 patients, 15 had received chemotherapeutic treatment, and the tumour specimen was obtained at the time of rescue mastectomy. The rest had received no treatment whatsoever.

\section{RT-PCR}

RNA was extracted from the tumour specimens with the RNeasy ${ }^{\mathrm{TM}}$ commercial kit (Ambion Inc), in accordance with the manufacturer's instructions. The total RNA content was immediately quantified in a spectrophotometer (GeneQuant pro RNA/DNA calculator ${ }^{\circledR}$; Amersham Pharmacia Biotech, Uppsala, Sweden) after dilution 1:10 in
Figure 1

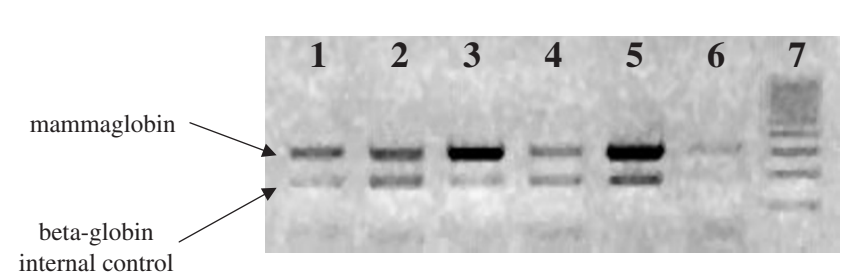

Reverse transcriptase-polymerase chain reaction (RT-PCR) analysis of mammaglobin expression in human breast cancer. $N=128$. Lanes 1-6, mammaglobin RT-PCR product (269 base pairs [bp]) above, $\beta$-globin internal control below; lane 7,100 bp ladder.

until further use. The RT-PCR reaction was performed in a thermal cycler with a commercial one-step RT-PCR kit (Ambion Inc). The primers used were 5'-GAA GTT GCT GAT GGT CCT CAT GCT GGC-3' (sense) and 5'-CTC ACC ATA CCC TGC AGT TCT GTG AGC-3' (antisense), and the conditions of RT-PCR were as follows: denaturing, $95^{\circ} \mathrm{C}$ for $30 \mathrm{~s}$; annealing, $62^{\circ} \mathrm{C}$ for $15 \mathrm{~s}$; elongation, $72^{\circ} \mathrm{C}$ for $20 \mathrm{~s}$ ( $30 \mathrm{cycles}$ ); and final cycle, $72^{\circ} \mathrm{C}$ for $7 \mathrm{~min}$. The primers encompass the whole open reading frame of the $h-M A M$ gene, which is made possible by the relatively small size of the three exons forming it $(44,189$ and 36 base pairs [bp], respectively). Furthermore, the presence of two comparatively large introns between them (604 and $1890 \mathrm{bp}$, respectively), avoids the appearance of false positive bands caused by co-amplification of contaminating DNA.

The $\beta$-globin gene was co-retrotranscribed and amplified in parallel under exactly the same conditions in a second tube as part of each reaction, using a set of extremely permissive primers and the same amount of mRNA, to function as an internal positive control (Fig. 1). Because $1 \mu$ l of the extracted RNA solution was used directly for RT-PCR, without further dilution, to obtain a homogeneous RNA concentration in all the samples, the band pairs in the different lanes of the gel shown in Fig. 1 have different intensities, reflecting the original RNA concentration corresponding to each tumour studied.

After amplification, $10 \mu \mathrm{l}$ of each product was run for $20 \mathrm{~min}$ in a $2 \%$ agarose gel at $100 \mathrm{~V}$, which was then stained with ethidium bromide. The bands were detected in a ultraviolet transilluminator, photographed with a Kodak Digital Science DC-40 ${ }^{\mathrm{TM}}$ digital camera and analysed by means of the 1D Image Analysis Software ${ }^{\mathrm{TM}}$ package, both from Eastman Kodak (Rochester, NY, USA). By means of the latter, we measured the net density of the bands. Dividing this by the net intensity of the control band ('differential PCR'), or by the initial RNA concentration of the sample, we obtained a measurement in arbitrary units that reflects, in comparison with that of the remaining samples, 
the relative expression of the gene under study in each of them. Both values were closely correlated with each other $(r=0.4537, P<0.0001)$ and were interchangeable for comparative purposes. Thus, after having processed onethird of the samples, and realising that we always obtained a measurable $h-M A M$ band, we decided to abandon the co-amplification of the $\beta$-globin gene and just used the relationship between the source RNA concentration and the final band density for quantifying $h-M A M$ expression, which halved our expenses on RT-PCR reagents.

\section{Immunohistochemistry}

The immunohistochemical technique employed was the standard one at our laboratory, and has been described extensively elsewhere [9]. In brief, $5 \mu \mathrm{m}$ paraffin sections were mounted on poly-L-lysine coated slides for heatinduced epitope retrieval ('HIER' technique) in citrate buffer. We used the same commercially available streptavidin-biotin-peroxidase kit (Histostain-SP; Zymed, San Francisco, California, USA) throughout the whole procedure, to ensure uniformity of results. The antibodies employed were as follows: NCL-CB11 (c-erb-B2), NCLER-6F11 (oestrogen receptor) and NCL-p53-D07 (p53), all from Novocastra Laboratories (Newcastle, UK); and prediluted MIB1 (Ki67) and PR-2C5 (progesterone receptor) from Zymed. The incubation time was $1 \mathrm{~h}$ at room temperature in a humid chamber for all antibodies, which, apart from the prediluted MIB1-Ki67 solution (which was directly used as supplied), were employed at the following dilutions: NCL-CB11 (c-erb-B2), 1:40; NCL-ER-6F11 (oestrogen receptor), 1:100; NCL-p53-D07, 1:100. The evaluation of nuclear staining patterns (oestrogen receptor, progesterone receptor, Ki67 and p53) was straightforward, because tumours positive for oestrogen receptor, progesterone receptor or p53 always showed specific staining in more than $10 \%$ of tumour cells. For p53, this tends to reflect adequately the expression of mutant p53 protein, as we have shown in the past by comparing p53 immunostaining and the detection of point mutations by means of single-strand conformation polymorphism [10]. In a later study [11], Schmitt and colleagues showed that tumours with less than one-third of the cells only moderately staining on immunohistochemistry had no detectable mutation of the p53 gene. If this more stringent criterion was applied to the tumours of our study, only 3 of the 21 with positive staining for p53 did so in less than one-third of the cells (one of them, however, very strongly in $20 \%$ of cells). Reassignment of the two cases with moderate staining in less than one-third of the cells, according to Schmitt and colleagues, would not alter the general results (see Table 2), so we adhered to our standard cutoff of 10\% throughout the study. The Ki67 labelling index was expressed as the percentage of reactive tumour cells. The tumours were considered to be positive for c-erb-B2 when more than $10 \%$ of cells showed complete specific membrane staining.

\section{Flow cytometry}

Fresh tumour tissue, kept in phosphate-buffered saline at $4^{\circ} \mathrm{C}$ until processing (not more than 24 hours later), was finely minced with a scalpel blade, mixed with $2 \mathrm{ml}$ of DNA-prep Stain reactant and $100 \mu$ of DNA-prep LPR reactant (both from Coulter Corporation, Miami, Florida, USA), and incubated for $30 \mathrm{~min}$ at $37^{\circ} \mathrm{C}$. The resulting mixture was then filtered through a $50 \mu \mathrm{m}$ pore filter and was then ready for cytometric analysis in a Coulter EPICS $\mathrm{XL}$ cytometer (Coulter Corporation). Analysis of the histograms obtained was performed with the help of the MultiCycle DNA Cell Cycle Analysis software package (Phoenix Flow Systems, San Diego, California, USA). Tumours were considered diploid when the DNA index obtained was 1.0, and aneuploid for any value diverging from 1.0, including tetraploid tumours, with a DNA index of 2.0.

\section{Statistics}

For comparative purposes with all other qualitative variables, the $h-M A M$ expression values, expressed in arbitrary units, were split into 'high' and 'low', using for this purpose the median value for the whole group (205.78 units) as a cut-off. All clinical and biological tumour variables potentially associated with high $h-M A M$ expression were individually tested in a univariate model (Table 1). Those associations attaining or showing a trend towards statistical significance were subsequently included in a multivariate model (Table 2), in which high $h$-MAM expression was taken as the dependent variable. This was done with the purpose of identifying clinical or biological features independently associated with $h-M A M$ expression, because many of the parameters tested in the tumours are known to be closely interrelated (for example, DNA ploidy and Ki67 labelling index). The statistical analysis was performed with the STATA statistical package (Stata Corporation, College Station, Texas, USA).

\section{Results}

RNA was obtained from all 128 tumour specimens, and the $h-M A M c-D N A$ was successfully retrotranscribed and amplified in all cases.

The expression level, quantified in arbitrary units as described above, ranged from 3.4 to 920.4 units.

From the univariate model, it can be seen that 'high' $h-M A M$ expression was correlated significantly with oestrogen receptor and progesterone receptor expression, diploid DNA content, low Ki67 labelling index and low nuclear grade, and almost significantly with absence of axillary nodal invasion in the mastectomy specimen. All these features, without exception, reflect a less aggressive tumour phenotype. There was no difference in $h-M A M$ expression between tumours from previously treated and untreated patients (Table 1), or between tumours belong- 
Table 1

\begin{tabular}{|c|c|c|c|c|c|}
\hline Variable & $n$ & $\begin{array}{c}\text { Mammaglobin } \\
>205.78^{\mathrm{a}}(\%)\end{array}$ & OR & $95 \% \mathrm{Cl}$ & $P$ \\
\hline \multicolumn{6}{|l|}{ Histology } \\
\hline Ductal + tubular & 108 & $52(48)$ & 1.00 & & \\
\hline Lobular & 20 & $12(60)$ & 1.62 & $0.61-4.30$ & 0.332 \\
\hline \multicolumn{6}{|l|}{ Chemotherapy } \\
\hline No & 15 & $55(49)$ & 1.00 & & \\
\hline Yes & 128 & $9(60)$ & 1.58 & $0.52-4.77$ & 0.412 \\
\hline \multicolumn{6}{|l|}{ Histological grade } \\
\hline $1+2$ & 60 & $32(53)$ & 1.00 & & \\
\hline 3 & 42 & $17(40)$ & 0.60 & $0.27-1.34$ & 0.203 \\
\hline \multicolumn{6}{|l|}{ Nuclear grade } \\
\hline $1+2$ & 52 & $30(58)$ & 1.00 & & \\
\hline 3 & 51 & $19(37)$ & 0.44 & $0.19-0.98$ & 0.039 \\
\hline \multicolumn{6}{|l|}{ Nodal metastasis } \\
\hline No & 70 & $40(57)$ & 1.00 & & \\
\hline Yes & 55 & $22(40)$ & 0.50 & $0.24-1.04$ & 0.058 \\
\hline \multicolumn{6}{|l|}{ DNA ploidy } \\
\hline$>1$ & 68 & $27(40)$ & 1.00 & & \\
\hline 1 & 60 & $37(62)$ & 2.44 & $1.17-5.08$ & 0.014 \\
\hline \multicolumn{6}{|l|}{ Oestrogen receptor } \\
\hline Negative & 34 & 12 (35) & 1.00 & & \\
\hline Positive & 93 & $52(56)$ & 2.33 & $1.01-5.34$ & 0.040 \\
\hline
\end{tabular}

Progesterone receptor

\begin{tabular}{lccccc} 
Negative & 62 & $23(37)$ & 1.00 & & \\
Positive & 66 & $41(62)$ & 2.78 & $1.32-5.84$ & 0.005 \\
$\begin{array}{l}\text { C-erbB-2 } \\
\text { Negative }\end{array}$ & 103 & $53(51)$ & 1.00 & & \\
Positive & 25 & $11(44)$ & 0.74 & $0.31-1.79$ & 0.505 \\
p53 & & & & & \\
Negative & 107 & $56(52)$ & 1.00 & & \\
Positive & 21 & $8(38)$ & 0.56 & $0.21-1.48$ & 0.235 \\
Ki67 & & & & & \\
$\leq 20 \%$ & 79 & $46(58)$ & 1.00 & & \\
$>20 \%$ & 49 & $18(37)$ & 0.42 & $0.20-0.88$ & 0.019 \\
\hline
\end{tabular}

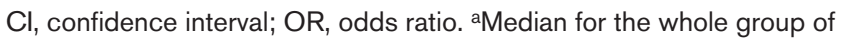
patients.

ing to different histological varieties of breast cancer. Eliminating the 15 previously treated patients from the analysis altered the results only slightly in the multivariate analysis, absence of nodal invasion was independently associated with high $h$-MAM expression in untreated patients; in contrast, if the whole group was considered, diploid DNA content and progesterone receptor expression retained statistical significance. However, as can clearly be seen from Table 2, the general trend is maintained throughout, whether or not previously treated patients are included in the analysis.

\section{Discussion}

Watson and Fleming [3] were the first to study mammaglobin expression by means of RT-PCR and Northern blotting in human breast cancer specimens. They studied 35 breast carcinomas of different histological varieties, and found $h-M A M$ to be overexpressed (at least 10-fold relative to normal breast tissue) in $23 \%$ of cases. This corresponds roughly to the 75th centile of our distribution expressed in arbitrary units, so both findings are superimposable. Ours also agree with those of Watson and colleagues in that mammaglobin expression is not bound to any particular histological variety of breast cancer. Again, Watson and colleagues studied the expression of mammaglobin in breast cancer by means of immunohistochemistry [10], and found a high immunoreactivity in $81 \%$ of tumours. There were once more no differences according to histological variety. Moreover, they detected mammaglobin mRNA by means of RT-PCR in 10 of 11 lymph nodes from patients with metastatic breast cancer, reflecting their colonisation by cells from the primary tumour.

This specificity of mammaglobin for breast epithelial cells has been widely used to detect circulating metastatic cells in the blood of breast cancer patients $[4,6]$. However, to our knowledge, mammaglobin expression has not previously been correlated with other clinical and biological features of the tumours, as we have done, to achieve a better understanding of its role in the oncogenic activation of breast ductal and lobular epithelial cells. Our results, in this sense, all point towards the same conclusion: that a high $h-M A M$ expression reflects a better differentiation, a lower proliferation rate and a higher hormone dependence of the tumours, all of which together define a better prognosis. This is corroborated by the fact that we also found in our series a significant inverse correlation between a high mammaglobin expression and the most important negative clinical prognostic factor for breast cancer, namely axillary nodal invasion.

There still remains the open question of whether this is attributable to a particular mechanism mediated by mammaglobin, or whether mammaglobin expression is just a feature of the normal breast epithelial cell that gets lost during the dedifferentiation process associated with increasing malignant transformation. However, it seems that things might not be as simple as that. Watson and Fleming [3] reported that $h-M A M$ mRNA levels tend to be 
Table 2

\begin{tabular}{|c|c|c|c|c|c|c|}
\hline \multirow[b]{2}{*}{ Variable } & \multicolumn{3}{|c|}{ All patients } & \multicolumn{3}{|c|}{$\begin{array}{l}\text { Excluding patients with } \\
\text { previous chemotherapy }\end{array}$} \\
\hline & OR & $95 \% \mathrm{Cl}$ & $P$ & OR & $95 \% \mathrm{Cl}$ & $P$ \\
\hline \multicolumn{7}{|c|}{ Nodal metastasis } \\
\hline No & 1.00 & & & 1.00 & & \\
\hline Yes & 0.51 & $0.24-1.10$ & 0.087 & 0.33 & $0.14-0.78$ & 0.011 \\
\hline \multicolumn{7}{|c|}{ DNA ploidy } \\
\hline$>1$ & 1.00 & & & 1.00 & & \\
\hline 1 & 2.25 & $1.05-4.80$ & 0.036 & 2.23 & $0.99-5.00$ & 0.053 \\
\hline \multicolumn{7}{|l|}{ PR } \\
\hline No & 1.00 & & & 1.00 & & \\
\hline Yes & 2.86 & $1.34-6.11$ & 0.007 & 3.06 & $1.32-7.09$ & 0.009 \\
\hline
\end{tabular}

$\mathrm{Cl}$, confidence interval; OR, odds ratio.

higher in tumours than in the corresponding normal breast tissue, something we also found in the course of our investigation. In fact, of the 45 normal tissues from the operated breasts containing the studied tumours available to us, $29(64.4 \%)$ showed lower mammaglobin expression levels than those of the corresponding tumours, whereas the contrary was true of the remaining 16 normal tissues. However, we are reluctant to derive any conclusions from these findings because of the small sample size, on the one hand, and the doubts about how normal is 'normal' breast tissue from a breast in which cancer has already arisen, on the other. In fact, this fundamental question is the main subject of our continuing investigation.

Finally, the possibility remains that mammaglobin expression might be hormonally regulated, and that all other features associated with a less aggressive phenotype might be a by-product of hormonal activity. In favour of this hypothesis stands our finding of a significant association between high $h-M A M$ levels and hormone receptor expression in the studied tumours, and a previous report by Zach and colleagues [4], who found elevated circulating levels of $h-M A M$ mRNA to be significantly associated with the presence of tumours positive for oestrogen receptor.

\section{Conclusion}

In conclusion, high mammaglobin expression in breast cancer is associated with a significantly less aggressive tumour phenotype. Further studies are needed to clarify whether this is attributable to $h-M A M$ expression itself or to another mechanism of which mammaglobin expression forms part.

\section{Competing interests}

None declared.

\section{References}

1. Watson M, Darrow C, Zimonjic D, Popescu N, Fleming T: Structure and transcriptional regulation of the human mammaglobin gene, a breast cancer associated member of the uteroglobin gene family localized to chromosome $11 \mathrm{q} 13$. Oncogene 1994, 16:817-824.

2. Ni J, Kalff-Suske M, Gentz R, Schageman J, Beato M, Klug J: All human genes of the uteroglobin family are localized on chromosome 11q12.2 and form a dense cluster. Ann NY Acad Sci 2000, 923:25-42.

3. Watson M, Fleming $\mathrm{T}$ : Mammaglobin, a mammary-specific member of the uteroglobin gene family, is overexpressed in human breast cancer. Cancer Res 1996, 56:860-865.

4. Zach O, Kasparu H, Krieger O, Hehenwarter W, Girschikowski M, Lutz D: Detection of circulating mammary carcinoma cells in the peripheral blood of breast cancer patients via a nested reverse transcriptase polymerase chain reaction assay for mammaglobin mRNA. $J$ Clin Oncol 1999, 17:2015-2019.

5. Grünewald K, Haun M, Fiegl M, Urbanek M, Müller-Holzner E, Massoner A, Riha K, Propst A, Marth C, Gastl G: Mammaglobin expression in gynecologic malignancies and malignant effusions detected by nested reverse transcriptase-polymerase chain reaction. Lab Invest 2002, 82:1147-1153.

6. Grünewald K, Haun M, Urbanek M, Fiegl M, Müller-Holzner E, Gunsilius E, Dünser M, Marth C, Gastl G: Mammaglobin gene expression: a superior marker of breast cancer cells in peripheral blood in comparison to epidermal-growth-factor receptor and cytokeratin-19. Lab Invest 2000, 80:1071-1077.

7. Kataoka A, Mori M, Sadanaga N, Ueo H, Tsuji K, Rai Y, Barnard GF, Sugimachi K: RT-PCR detection of breast cancer cells in sentinel lymph modes. Int J Oncol 2000, 16:1147-1152.

8. Colpitts TL, Billing-Medel P, Friedman P, Granados EN, Hayden M, Hodges S,Menhart N, Roberts L, Russell J, Stroupe SD: Mammaglobin is found in breast tissue as a complex with BU101. Biochemistry 2001, 40:11048-11059.

9. Schneider J, Pollán M, Jiménez E, Ruibal A, Lucas AR, Núñez MI, Sánchez J, Tejerina A: Histologic grade, Ki67 and CD44 are predictors of axillary lymph node invasion in early (T1) breast cancer. Tumour Biol 1999, 20:319-330.

10. Schneider J, Rubio MP, Rodríguez-Escudero FJ, Seizinger BS, Castresana JS: Identification of p53 mutations by means of 
Breast Cancer Research Vol 5 No 3 Núñez-Villar et al.

SSCP (single strand conformation polymorphism) analysis in gynaecologic tumors: comparison with the results of immunohistochemistry. Eur J Cancer 1994, 30A:504-508.

11. Schmitt FC, Soares R, Cirnes L, Seruca R: p53 in breast carcinomas: association between presence of mutation and immunohistochemical expression using a semiquantitative approach. Pathol Res Pract 1998, 194:815-819.

\section{Correspondence}

Professor J Schneider, Fundación Tejerina, Calle José Abascal 40,

E-28003 Madrid, Spain. Tel: +34 91399 4280; fax: +34 91446

0253; e-mail: schneider@teleline.es 